\title{
ПоЛИТОЛОГИЯ
}

DOI: http://dx.doi.org/10.15688/jvolsu4.2016.2.12

UDC 329.11(470+571)

Submitted: 22.10 .2015

LBC 66.1(2)-17

Accepted: 30.03 .2016

\section{STABILIZING AND CONSOLIDATING RESOURCES OF CONSERVATISM IN RUSSIA}

Part $2^{1}$

\section{Konstantin A. Lotarev}

Candidate of Sciences (Politics), Senior Researcher,

Department of Science, Innovation and Research Training,

Volgograd State University

lotarev16@mail.ru

Prosp. Universitetsky, 100, 400062 Volgograd, Russian Federation

\begin{abstract}
The author believes that the governmental regulation of a society is one of the bases of conservatism. He thinks that the state exists in order to protect society and a person from forcible manifestations and free understanding of personal liberty, from non-state coercion and even violence, from manifestation of egoistical personal and corporate interests. Power of the state considerably increases when it relies on traditions of the past rather than the ideals of the future.

The conservatism as a political trend historically developed as force fastening a public organism. The author of this article believes that only conservatism possesses the real stabilizing resources capable to consolidate society of modern Russia. The author also recognizes that nowadays government and public institutes make certain efforts for overcoming certain social diseases.

The continuity and progressiveness of the state and social development define fundamentals of ontology of conservatism as the world outlook and a political trend. The Russian State is still at the stage of transition period. The formation of strong democratic institutes has not yet been completed. One of the main problems is the need for public consolidation. Now only the conservatism has sufficient resources and opportunities for the solution of this problem.
\end{abstract}

Key words: conservatism, world outlook, ideology, society consolidation, political culture, civil society.

УДК 329.11(470+571)

Дата поступления статьи: 22.10.2015

ББК 66.1(2)-17

Дата принятия статьи: 30.03.2016

\section{СТАБИЛИЗИРУЮЩИЕ И КОНСОЛИДИРУЮЩИЕ РЕСУРСЫ КОНСЕРВАТИЗМА В РОССИИ}

\author{
YACTb $2^{1}$
}

\section{Константин Анатольевич Лотарев}

Кандидат политических наук, старший научный сотрудник

управления науки, инноваций и подготовки научных кадров, 
Волгоградский государственный университет

lotarev16@mail.ru

просп. Университетский, 100, 400062 г. Волгоград, Российская Федерация

Аннотация. Одной из основ консерватизма является государственное регулирование общества. Государство существует для того, чтобы охранять общество и человека от волюнтаристских проявлений и вольного понимания личной свободы, от негосударственного принуждения и даже насилия, от проявления эгоистических личных и корпоративных интересов. Автор считает, что мощь государства значительно возрастает, когда оно опирается на традиции прошлого, а не на идеалы будущего. Феномен консерватизма проявляется и в универсальности, и в индивидуальности вариантов. Консерватизм всегда национален и в силу этого отличается разнообразием проявлений в практической политике. Главная особенность консерватизма по сравнению с либерализмом и социал-демократией состоит в том, что как идеология он обретает определенные формы только в периоды необходимых преобразований или значимых политических процессов. Консерватизм как идеология и политическое течение формируется на фундаменте мировоззренческом, и в этом состоит его универсализм. Консерватизм неотделим от государственных концептов и опирается всегда на мощь государственных ресурсов, видя в них основной инструмент стабилизационной и консолидирующей политики.

Ключевые слова: консерватизм, мировоззрение, идеология, консолидация общества, политическая культура, гражданское общество.

В ходе революционного процесса начала $\mathrm{XX}$ в. и большевистского переворота в октябpe 1917 г. Российская империя прекратила свое существование. Россия трансформировалась в СССР - по сути, в новую империю, но империю в консервативном аспекте искусственную, неестественную в сопоставлении с развитием европейской цивилизации. В социал-демократическом движении Европы первой трети XX в. преобладало умеренное большинство, далекое от российского радикального большевизма. Западные социал-демократы привнесли и развили новые социально-политические ценности, но вместе с этим и признали сложившееся мироустроение в своих государствах, отношения собственности, законодательство и исторически установленный социальный порядок. Ситуация в России была совершенно иной. Трансформации подверглось все - государственный строй, законодательство, социально-экономические отношения, социальное устройство, органическое строение и состояние культуры в целом, методология научного познания. Радикально создавалась новая система ценностей и также радикально эта утопическая система утверждалась посредством насилия и прямого террора - от диктатуры пролетариата до диктатуры командно-административной системы. Только за одно XX столетие сменили друг друга пять конституций. Эта смена конституций осуществлялась не по необходимости по- литического и социально-экономического развития, а в большей мере по амбициозным стремлениям властей, руководствующихся своими идеологическими конструктами и представлениями (конституции 1918, 1924, 1936, 1977 гг.). Только конституция 1993 г. является Основным законом современной России, которая встала на путь возвращения в идейно-ценностных представлениях к естественному рыночному и демократическому цивилизационному развитию.

Исходя из динамичности и противоречивости отечественной политической истории, можно констатировать, что социальные ценности, обладая известной прочностью, тем не менее подвержены ситуативной политической коррозии. При этом значительную роль в современном мире играют системы социальногосударственных коммуникаций, которые в состоянии весьма эффективно манипулировать общественным сознанием и формировать его соответствующим образом. Проблема ценностного конфликта и консенсуса в Российской Федерации осложняется еще и тем, что новые трансформационные процессы, начавшиеся с 1991 г., не обрели еще системного и целенаправленного характера в социальной и культурной сфере. Одной из главных причин этого является то, что современное общество не имеет еще относительно сложившейся стратификации, нет самодостаточного среднего класса, отсутствуют развитые и реально дей- 
ствующие институты гражданского общества и системная в своей выверенной направленности социальная и культурная политика государства. В политическом развитии государства и общества, сопряженного со значительными политическими, экономическими и социокультурными трансформациями, происходящими в относительно короткий промежуток времени, социальные ценности неизбежно коррелируются с политическими ценностями или приобретают политическое значение.

В эпоху СССР начался и закончился социалистический эксперимент. Политическое учение коммунизма было направлено на уничтожение всего исторически сложившегося в России. Большевистское государство оказалось единственной культурно-ценностной монополией и приступило к утверждению в сознании общественных слоев материалистической трактовки социального бытия, коллективистского антисобственнического сознания. Социал-реформизм Западной Европы отличался куда большей умеренностью. Крайний радикализм и нетерпимость в Европе не возобладали. Исключением может считаться время национал-социалистской Германии - главной виновницы развязывания Второй мировой войны.

Советский строй начал утверждаться с уничтожения церкви и веры, хозяйственно-экономической, культурной и научной элиты; в сознание большинства малообразованного народа внедрили конгломерат искусственных ценностей, одновременно с этим уничтожая лучших людей. Социальный гумус, складывавшийся в России веками, был серьезно и основательно подорван. Социальная стабильность поддерживалась колхозным закабалением сельских областей и искусственно завышенной заработной платой рабочих. Интеллигенция обрела статус прослойки и была весьма уязвима во всех отношениях.

Советский эксперимент закончился тупиком и распадом СССР. Но осталось слабоструктурированное общество в контексте весьма размытой ценностной составляющей, а ведь именно ценностные системы представлений и так или иначе укорененные в сознании общественных слоев идеологические конструкты придают общественным стратам устойчивость и самодостаточность.
Российское государство вновь вышло на путь естественного развития, путь, по которому идет весь цивилизованный мир. Представляется, что выход из исторического и политического кризиса (коммунистического тупика) оказывается более сложным и медленным, чем вхождение в него посредством большевистского переворота и диктатуры. При складывании рыночных отношений, реальной демократии и гражданского общества, могущих быть основанными только на отношениях собственности и высокой политической и правовой культуре, радикальная внутренняя политика 90-х гг. приняла либеральное направление при всех своих особенностях, своеобразии и методах продвижения. Эти особенности либеральной радикальной политики были определены многими обстоятельствами. Одно из них - необходимость утверждения качественно иных ценностных идеологических конструктов. Утверждение в общественном сознании уважения к частной собственности, предпринимательству и коммерции, рыночной экономике, демократии и парламентаризму было невозможно без ценностей либерализма. Но как проводилась либеральная политика и какой общественный резонанс вызвала со временем на фоне негативных реальностей, возникших по причине недальновидности власти, - другой вопрос. При слабой структурированности постсоветского общества основные элементы либеральной идеологии нашли немало сторонников в обществе - признание позитивности индивидуальной инициативы в частных, гражданских и государственных делах; признание и восприятие идеи разделения властей, политического плюрализма в политико-административной практике.

Вместе с тем на фоне бедности и незащищенности большинства общества радикально внедряемые в общественное сознание теоретические либеральные ценности индивидуальной свободы, самодостаточности личности, первичности индивидуализма вызвали неприятие и критику. И отнюдь не либерализм оказался виновным в том, что в обществе весьма заметными стали проявления правового нигилизма и коррупции. Современные телевидение и Интернет разделены на позитивные и негативные зоны. От негативных зон, процветающих на волне всеподчинения среб- 
ролюбию, защиты практически нет. Демонстрация в гипертрофированном виде диких инстинктов, картин изощренного насилия, табуированной лексики, низкопробных творений «творческих личностей» во многих областях творчества наносит значительный вред. Демонстраторы вышеназванного отстаивают идею о недопустимости цензуры и любой формы контроля.

Российское государство во все периоды своей многотрудной истории представляло и представляет собой единицу планетарного масштаба. Огромная территория и системообразующий русский народ, потративший колоссальные усилия на сохранение и увеличение мощи своего государства, достойны куда лучшей участи.

Верховная власть - великокняжеская, царская, императорская - проводила, как правило, дальновидную и взвешенную этническую политику. Народы, так или иначе вошедшие в состав России, сохраняли и свой уклад, и общественные отношения со сложившейся иерархией. Национальная знать автоматически становилась знатью и Российского государства.

Культура и наука России также представляют собой явления планетарного масштаба. В силу сложившегося мирового статуса России многие политические и социальные ценности следует воспринимать в контексте мироощущения русского народа, поскольку он доминирует численно и является основой государства. Это не означает вольного или невольного нанесения морального и какого бы то ни было ущерба другим народам Российской Федерации, защищенным положениями конституции. В консервативном аспекте глубоко укоренившиеся социально-политические ценности непреходящего характера - государство, вера, народ, правда, справедливость, порядок - прочно составляют фундамент менталитета подавляющего большинства населения нашей страны. Гуманитарно образованные люди, исторически укорененные и органично воспринимающие русскую культуру, придают этим ценностям особое значение. Это не просто слова и категории. Это данности, за которыми стоит многовековая и многотрудная история народа и государства. Государство неизбежно воспринимается в контек- сте могущества и державности, как и народ, этим данностям соответствующий. Православная церковь в настоящее время постепенно восстанавливает свою роль и значение. Принимая во внимание исторически сложившуюся многоконфессиональность России, заметим, что все вероисповедания возвращают себе былое значение. Правда, справедливость и порядок, как представляется, пребывают еще в несколько виртуальном состоянии. В консервативном аспекте эти ценности вообще едва ли могут пребывать в реально функциональном состоянии по причине несовершенной природы человека, но государство как основной институт политической системы общества может и обязано максимально действенно утверждать в реальности эти важнейшие социальные ценности, скрепляющие и консолидирующие все общество. Для этого необходима длительная и непрерываемая консервативная политическая традиция, утраченная Россией. Вместе с тем вполне заметен постепенный процесс реставрации этой традиции.

В последнее десятилетие власть, обладающая всей мощью информационных ресурсов, осуществляет многоплановые экономические и социально-политические инициативы. Цель Правительства Российской Федерации - придать внутриполитическому курсу стабильность и определенность, лишенные былой либерально-реформистской фронды. На смену радикальному псевдолиберализму, негативно воспринятому обществом, пришла более умеренная и сдержанная консервативная политика.

В настоящее время партия «Единая Россия» не называет себя определенно консервативной партией, но по сути своей проводимая ею внутренняя и внешняя политика не противоречит основным элементам консервативной политики. В политическом спектре «Единая Россия» позиционирует себя как партия, опирающаяся на консервативные идеи и ценности. Приходится признать: на уровне массового сознания имеет место искаженное понимание феномена консерватизма и его онтологических основ. На одном из примеров покажем, как обращаются с категорией «консерватизм» составители пробных вариантов ЕГЭ по отечественной истории и транслиру- 
ют свое невежественное понимание выпускникам средних школ: «Что свидетельствовало о повороте руководства СССР при Л.И. Брежневе к консервативному курсу после хрущевской оттепели?» [2, с. 143] и далее «Консерватизм партийно-государственного аппарата» [2, c. 198]. Подобные смысловые построения нередки. Их можно объяснить тем, что само слово «консерватизм» обладает высокой степенью привлекательности, красоты и солидности. Но обходятся с ним нередко с точностью до наоборот, используют его не понимая глубины и смысла и не к месту [5, с. 98-99]. Очевидной становится необходимость утверждать в общественном сознании правильное понимание природы консерватизма, сложности его форм и проявлений. К сожалению, вышеотмеченное вульгарное обращение с терминологией нередко встречается и на страницах монографий, опубликованных в советское время, и на страницах современной научной периодики. Представляется верным и обоснованным в методологическом отношении суждение о качественных отличительных составляющих консерватизма, охранительства и реакции, проявляющих себя в определенных процессах и событиях, а также своеобразии того или иного временного периода (см. подробнее: [3, с. 77-79]). Остается только напомнить отношение англичан к консерватизму. Интегрируя все его оценки, они говорят вслед за Уинстоном Черчиллем, что история мало кого удостоила чести называться консерватором.

Онтологические основания консерватизма состоят в признании ценности опыта предков, убеждении, что общество и государство есть сложные органические системы. Консерваторы не отрицают многообразия форм социального бытия, убеждены в ограниченных возможностях человеческого разума, считают, что роль государства неизбежно велика, поскольку только оно в решающих ситуациях способно объединить общество и придать политическому процессу единство позитивного действия. Консерваторы пессимистичны в оценке человеческой природы, честно говорят о невозможности социального равенства. Зло и несправедливость в этом мире неизбежны, поскольку неизбежны социальные различия. Их невозможно уничтожить, но можно и необходимо максимально нивелировать. И этого способно достигать только государство, а не разрозненные социальные анклавы или лидеры-одиночки, временно находящиеся у власти.

На одном из заседаний Комитета министров в 1904 г. его председатель С.Ю. Витте говорил: «Горе той стране, которая не воспитала в населении чувства законности и собственности, а, напротив, насаждала разного рода коллективное владение» (цит. по: [1, с. 164]).

В современности этих слов едва ли кто может теперь усомниться. Частная собственность и законопослушность есть гарантии личных свобод и социальной гармонии. В странах Европы консерватизм эволюционировал беспрепятственно, но в России эволюция консерватизма была прервана большевистским переворотом. Но цикличность развития консерватизма неизбежна, поскольку не учитывать динамику социального и государственного развития не может ни одна идеология и доктрина.

Экономические составляющие играют важную роль в жизни общества, но без идеологических конструктов едва ли экономическое развитие России будет стабильным и позитивным. Одной из важных отличительных черт консерватизма является его органическая привязанность к национальному своеобразию. Другими словами, консерватизм всегда национален. В силу этого верным можно считать констатацию, что «попытка заимствования западной модели экономического консерватизма и ее наложение на опыт и реалии российских реформ бесперспективна, так как макро- и микропоказатели, факторы, условия и цели различных социально-экономических систем весьма отличны (при кажущейся схожести структурных составляющих)» [4, с. 117].

Опираясь исключительно на здравый смысл, жизненный опыт и знания, консерваторы - теоретики и практики прошлого и настоящего - показывают основательность и прозорливость. В этом контексте примечательной представляется статья И.В. Тушканова, рассмотревшего политико-правовые взгляды ярких представителей консервативной мысли России - К.Н. Леонтьева и Н.Я. Данилевского. Говоря об основных положениях цивилизационного подхода, справедливо 
отмечается что «общечеловеческой» цивилизации не существует, как не существует и не может существовать «всечеловеческой» цивилизации, ибо этот идеал достижим лишь совместным развитием всего человечества в прошлом, настоящем и будущем. Исходя из таких посылок и утверждается, что цивилизация не передается <..> от народов одного культурного типа народам другого» [8, с. 111]. И далее отмечается, что взаимодействие цивилизаций не исключается, но оно возможно и полезно «только при сохранении народами своих самобытных основ» [8, с. 111].

Консерватизм, в отличие от либерализма и социал-демократии, менее всего идеологичен, поскольку изначально выступает противником умозрительных теорий. Но в реальной политике, сталкиваясь с конкурентами, консерваторы вынуждены облекать свои органически естественные для социума идеи в идеологические системы. Представляется ненаучным употребление понятия «консерватизм» в каком бы то ни было контексте, связанном с радикальными коммунистическими представлениями. Иными словами, консерватизм несовместим с подобными идеологиями. Более того, консерватизм не является «брендом», в борьбе за обладание которым якобы ведут борьбу некоторые политические институты (группы давления, партии и т. п.) [6]. С. Ф. Хантингтон, предложивший понимать консерватизм как ситуационный феномен, теоретически предопределил довольно широкое понимание, позволяющее некоторым исследователям видеть консервативное в «ситуационных реакциях» различных политических сил. Подобное понимание, впрочем, довольно быстро рушится при анализе различных интерпретаций таких понятий и категорий, как государство, собственность, религия и др. либералами, коммунистами, социал-демократами и прочими политическими силами. Относительно практических аспектов реальной политической и социальной ситуации в России представляется обоснованным заключение, что «сама политическая стратегия государственной власти не является результатом преобладания социальных групп и слоев населения, чей экономический, общественный и политический статус предполагает ориентацию на консер- вативную идеологию. Отсутствие таких социальных групп и слоев само по себе является причиной, в которой государство обречено на мунипулятивные политические стратегии, апеллирующие к воле большинства как воли всех» $[7$, с. 100].

В итоге отметим: проблема конфликта ценностей в современной России вполне решаема. Идеологии имеют свойство конвергироваться в некоторых элементах.

Достижение стабильной социальной реальности возможно только при решении важнейших проблем: преодоление бедности, достижение высокого уровня инновационной экономики, стабильная и ориентированная образовательная и культурная политика, совершенное законодательство и реальные правоприменение и правозащита, преодоление правового нигилизма и формирование законопослушного социума, оформление среднего класca - основного гаранта функционирования гражданского общества и демократии.

В развитых странах Европы консерватизм, сохраняя свои основы, нередко трансформируется в неоконсерватизм. Неоконсервативная доктрина, состоящая из сбалансированных либеральных и консервативных ценностей, могла стать в середине 90-х гг. опорой социального согласия, способной объединить умеренные силы социалистического, либерального и национал-патриотического движений, придать процессу реформирования российского общества и государства столь необходимую стабильность и преемственность.

Перспективность объединяющей общество консервативной доктрины будет определяться следующими ее элементами: осознанием самобытности политической истории России и вместе с тем признанием определенной зависимости от европейской; утверждением приоритета в политическом сознании и политической культуре нации гражданских прав, демократии, собственности и широких возможностей их реализации, основанных на ответственности и чувстве долга; утверждением либерального принципа равенства всех перед законом; традиционными социалистическими ориентациями в обществе: всеобщим правом на образование, здравоохранение, совершенствуемой системой социального обес- 
печения, значительной ролью государства в сфере регулируемой рыночной экономики; утверждением незыблемости консервативного принципа сильной демократической государственности и взаимной ответственности государства и гражданина.

\section{ПРИМЕЧАНИЕ}

1 Часть первая опубликована: Вестник Волгоградского государственного университета. Серия 4, История. Регионоведение. Международные отношения. 2014. № 6 (30). С. 91-99.

\section{СПИСОК ЛИТЕРАТУРЫ}

1. Белковец, Л. П. История государства и права России. Курс лекций / Л. П. Белковец, В. В. Белковец. - Новосибирск : Новосиб. книж. изд-во, 2000. $216 \mathrm{c}$.

2. Гевуркова, Е. А. ЕГЭ 2009. История. Сборник заданий / Е. А. Гевуркова, В. И. Егорова, Л. И. Ларина. - М. : Эксмо, 2009. - 240 с.

3. Кузнецов, О. В. Консерватизм, охранительство, реакция: понятие и содержание / О. В. Кузнецов // Идеология консерватизма в России : материалы 1 науч.-практ. конф. (г. Волгоград, 1 июня 2004 г.) / К. А. Лотарев [и др.] ; под ред. А. И. Орлова. Волгоград : Волгогр. науч. изд-во, 2005. - 224 с.

4. Огарков, А. А. Российский экономический консерватизм / А. А. Огарков // Идеология консерватизма в России : материалы 1 науч.-практ. конф. (г. Волгоград 1 июня 2004 г.) / К. А. Лотарев [и др.] ; под ред. А. И. Орлова. - Волгоград : Волгогр. науч. изд-во, 2005. - 224 с.

5. Павлов, Д. Ю. Социально-политические проблемы консолидации современного российского общества / Д. Ю. Павлов // Ученые записки Российского государственного социального университета. - 2010. - № 9. - С. 93-100.

6. Пантелеев, С. Русский консерватизм сегодня (битва за бренд) / С. Пантелеев // Свободная мысль. - 2004. - № 1. - С. 45-62.

7. Пилипенко, В. А. Консервативные ценности в общественном сознании Россиян и политическое будущее «Российского консерватизма» / В. А. Пилипенко // Идеология консерватизма в России : материалы 1 науч.-практ. конф. (г. Волгоград, 1 июня 2004 г.) / К. А. Лотарев [и др.] ; под ред. А. И. Орлова. - Волгоград : Волгогр. науч. изд-во, 2005. -224 с.

8. Тушканов, И.В.Цивилизационный подход в политико-правовых учениях русских монархистов второй половины XIX века / И. В. Тушканов // Научный вестник ВАГС. - 2010. - № 2. - С. 106-111.

\section{REFERENCES}

1. Belkovets L.P., Belkovets V.V. Istoriya gosudarstva i prava Rossii. Kurs lektsiy [History of State and Law of Russia. Lecture Course]. Novosibirsk, Novosibirskoe knizhnoe izd-vo, 2000. 216 p.

2. Gevurkova E.A., Egorova V.I., Larina L.I. $E G E$ 2009. Istoriya. Sbornik zadaniy [Single State Examination 2009. History. Collection of Tasks]. Moscow, Eksmo Publ., 2009. 240 p.

3. Kuznetsov O.V. Konservatizm, okhranitelstvo, reaktsiya: ponyatie i soderzhanie [Conservatism, Protection, Reaction: Concept and Content]. Lotarev K.A., et al. Ideologiya konservatizma v Rossii: materialy 1 nauchno-prakticheskoy konferentsii ( $g$. Volgograd, 1 iyunya 2004 g.) [Ideology of Conservatism in Russia: Proceedings of the $1^{\text {st }}$ Scientific and Practical Conference (Volgograd, June 1, 2004)]. Volgograd, Volgogradskoe nauchnoe izd-vo, 2005. 224 p.

4. Ogarkov A.A. Rossiyskiy ekonomicheskiy konservatizm [Russian Economic Conservatism]. Lotarev K.A., et al. Ideologiya konservatizma v Rossii: materialy 1 nauchno-prakticheskoy konferentsii ( $g$. Volgograd, 1 iyunya 2004 g.) [Ideology of Conservatism in Russia: Proceedings of the $1^{\text {st }}$ Scientific and Practical Conference (Volgograd, June 1, 2004)]. Volgograd, Volgogradskoe nauchnoe izd-vo, 2005. 224 p.

5. Pavlov D.Yu. Sotsialno-politicheskie problemy konsolidatsii sovremennogo rossiyskogo obschestva [Socio-Political Problems of Consolidation of Modern Russian Society]. Uchenye zapiski Rossiyskogo gosudarstvennogo sotsialnogo universiteta, 2010, no. 9, pp. 93-100.

6. Panteleev S. Russkiy konservatizm segodnya (bitva za brend) [Russian Conservatism Today (Battle for the Brand)]. Svobodnaya mysl, 2004, no. 1, pp. 45-62.

7. Pilipenko V.A. Konservativnyie tsennosti v obschestvennom soznanii Rossiyan i politicheskoe budushchee "Rossiyskogo konservatizma" [Conservative Values in the Public Consciousness of Russians and the Political Future of "Russian Conservatism"]. Ideologiya konservatizma v Rossii: materialy 1 nauchno-prakticheskoy konferentsii ( $g$. Volgograd, 1 iyunya 2004 g.) [Ideology of Conservatism in Russia: Proceedings of the $1^{\text {st }}$ Scientific and Practical Conference (Volgograd, June $1,2004)]$. Volgograd, Volgogradskoe nauchnoe izd-vo, 2005. $224 \mathrm{p}$.

8. Tushkanov I.V. Tsivilizatsionnyy podkhod v politiko-pravovykh ucheniyakh russkikh monarkhistov vtoroy poloviny XIX veka [Civilizational Approach in Political and Legal Studies of Russians Monarchists in the Second Half of the 19th Century]. Nauchnyy vestnik VAGS, 2010, no. 2, pp. 106-111. 